AGrária

Revista Brasileira de Ciências Agrárias

ISSN (on line): 1981-0997

v.7, n.1, p.180-188, jan.-mar., 2012

Recife, PE, UFRPE. Www.agraria.ufrpe.br

DOI:10.5039/agraria.v7i1a914

Protocolo 914 - 21/04/2010 *Aprovado em 08/07/2011

Pablo T. L. de Oliveira ${ }^{1}$

Silvia H. N. Turco²

Gherman G. L. de Araújo $0^{3,5}$

Tadeu V. Voltolini 3,6

Daniel R. Menezes²

Thieres G. F. da Silva ${ }^{4}$

${ }^{1}$ Instituto Federal de Educação, Ciência e Tecnologia do Sertão Pernambucano, BR 235, KM 22, Projeto Senador Nilo Coelho - N4, CEP 56300-000, PetrolinaPE, Brasil. Fone: (87) 3862-1885. E-mail: pablo.leal@ifsertao-pe.edu.br

${ }^{2}$ Fundaçãa Universidade Federal do Vale do São Francisco, Colegiado Acadêmico de Engenharia Agrícola e Ambiental e Colegiado Acadêmico de Medicina Veterinária, respectivamente, Avenida Antonio Carlos Magahães, 510, Santo Antônio, CEP 48902-300, Juazeiro-BA, Brasil. Fone: (74) 3614-1934. E-mail: silvia.turco@univasf.edu.br; daniel.menezes@univasf.edu.br

${ }^{3}$ Empresa Brasileira de Pesquisa Agropecuária, Centro de Pesquisa Agropecuária do Trópico Semi-Árido, BR428, km152, Zona Rural, CEP 56302-970, Petrolina-PE, Brasil. Caixa Postal 23. Fone: (87) 3862-1711 Ramal 158. Fax: (87) 3862-1744. E-mail: ggla@cpatsa.embrapa.br;

tadeu.voltolini@cpatsa.embrapa.br

${ }^{4}$ Universidade Federal Rural de Pernambuco, Unidade Acadêmica de Serra Talhada (UAST), Fazenda Saco, s/n, Zona Rural, CEP 56900-000, Serra Talhada-PE, Brasil. Caixa Postal 63. Fone: (87) 3831-2206. E-mail: thigeoprofissional@hotmail.com

${ }^{5}$ Bolsista de Produtividade em Pesquisa do CNPq

${ }^{6}$ Bolsista de Produtividade em Desenvolvimento

Tecnológico e Extensão Inovadora do CNPq

\section{Comportamento ingestivo e parâmetros fisiológicos de bovinos Sindi alimentados com teores crescentes de feno de erva-sal}

\section{RESUMO}

Objetivou-se avaliar o efeito das variáveis meteorológicas e das dietas com diferentes níveis de feno de ervasal (Atriplex nummularia Lindl.) e palma forrageira (Opuntia fícus indica Mill) sobre as respostas horárias dos parâmetros fisiológicos e comportamento ingestivo dos novilhos da raça Sindi. Foram utilizados oito animais da raça Sindi, distribuídos em quadrado latino duplo com quatro tratamentos: 15, 30, 45 e 60\% de inclusão de feno de erva-sal, em quatro períodos. As variáveis meteorológicas ao longo do dia exerceram forte influência sobre todas as respostas fisiológicas dos animais. Entretanto, a distribuição das atividades do comportamento ingestivo (alimentação, ruminação e ócio), ao longo das 24 horas, foi ritmada pelos horários de distribuição do alimento, mostrando-se pouco influenciada pelas variáveis meteorológicas. 0 consumo das dietas experimentais, contendo os menores percentuais de feno de erva-sal pelos novilhos da raça Sindi, proporcionaram aumento na frequência respiratória dos animais, sem, no entanto, alterar a temperatura retal.

Palavras-chave: Bem-estar, bioclimatologia, palma forrageira, semiárido, temperatura.

\section{Ingestive behavior and physiological parameters of Sindhi cattle fed increasing levels of saltbush hay}

\section{ABSTRACT}

The aim of this study was to evaluate the effect of the meteorological variables and the diets with different saltbush hay (Atriplex nummularia Lindl.) and forage (Opuntia fícus indica Mill) levels on the hourly responses of the physiological parameters and ingestive behavior of Sindi steers. Eight Sindhi breed animals were allotted to a double Latin square with four treatments: $15,30,45$ and $60 \%$ inclusion of saltbush hay, in four periods. The meteorological variables throughout the day strongly influenced all physiological responses of the cattle. However, the distribution of the activities of ingestive behavior (eating, ruminating and idling), over 24 hours, was punctuated by the food distribution periods, proving to be little influenced by the meteorological variables. The consumption of the experimental diets containing the lowest percentage of saltbush hay by the Sindhi steers increased the respiratory rate of the animals, however, without changing the rectal temperature.

Key Words: Welfare, bioclimatology, forage cactus, semiarid, temperature. 


\section{INTRODUÇÃO}

O estresse calórico pode ser considerado um dos principais fatores limitantes à produção de bovinos em clima quente (Silva, 2000), pois as elevadas temperaturas podem interferir no consumo de alimentos (Beede \& Collier, 1986; Damasceno et al., 1998; Silanikove, 2000), no ganho de peso (Santos, 1999), nas taxas reprodutivas (Bényei \& Barros, 2000; Pires et al., 2002) e na produção de leite (Damasceno et al., 1998; Martello et al., 2004).

Em condições climáticas extremas, alguns comportamentos relacionados com a regulação do consumo e perda de água têm um papel importante na conservação da termoneutralidade nos homeotérmicos. Assim, a capacidade de resistir a ambientes áridos torna-se possível pela seleção de condições mais suaves que diminuem o estresse dos animais, podendo, até mesmo, evitar a necessidade de adaptações fisiológicas. Deste modo, os padrões de comportamento se constituem em um dos meios mais efetivos pelos quais os animais adaptam-se a diversos fatores ambientais, podendo indicar métodos potenciais de melhoramento da produtividade animal pelo uso de diferentes manejos.

Um aspecto importante na ingestão alimentar de ruminantes refere-se ao conhecimento dos horários de concentração do pastejo pelos animais. O comportamento ingestivo nos ruminantes varia devido a uma serie de fatores ligados ao alimento, ao ambiente e ao animal. Ao analisar o consumo de alimentos dos ruminantes, deve-se levar em consideração a composição químico-bromatológica da dieta, especialmente o teor de fibra em detergente neutro (FDN) e o tamanho da partícula (Fischer et al., 2002), ou até mesmo os horários, a frequência e os intervalos de tempo entre o arraçoamento (Chase et al., 1976; Jaster \& Murphy, 1983).

A palma forrageira (Opuntia ficus Mill) pode ser considerada um dos mais importantes e estratégicos recursos forrageiros do semiárido brasileiro. É extremamente resistente à seca e se destaca pelo seu potencial energético e aquoso. A sua composição química varia segundo a espécie, a cultivar e a idade do cladódio (Santos et al., 1992) e suas principais características são: alto conteúdo de água, minerais e carboidratos, além do seu baixo conteúdo de proteína. Ao contrário de outras forragens, a palma possui baixo percentual de parede celular e alta concentração de carboidratos nãofibrosos (Batista et al., 2003), tendo com isso, a necessidade da associação com outros tipos de volumosos.

Nos últimos anos, a erva-sal (Atriplex nummularia Lindl.) tem se mostrado, em várias regiões áridas e semiáridas do mundo, um importante recurso forrageiro na complementação de dietas para ruminantes. Segundo dados da FAO (1996), as características que dão importância à erva-sal como alternativa para a alimentação de ruminantes no semiárido nordestino são: alta resistência a condições de aridez, bom rendimento forrageiro, fácil propagação, alto poder calorífico e pouca susceptibilidade a pragas e doenças. No entanto, pode apresentar certa restrição, pois quando consumida isoladamente ocasiona redução do consumo, por apresentar elevada concentração de sais.
A ingestão alimentar em ruminantes, além de ser muito influenciada pelas condições climáticas, também é afetada pelo tipo de alimentos oferecidos na dieta, alterando, por sua vez, o comportamento alimentar, os níveis de produção e a taxa de fertilidade.

Em ambientes de temperaturas elevadas, nas quais a produção de calor excede a dissipação pelos animais, todas as fontes que geram calor endógeno são inibidas, principalmente o consumo de alimento, o metabolismo basal e energético, enquanto que a temperatura corporal, a frequência respiratória e a taxa de sudação aumentam (Souza et al., 2007). Segundo Neves et al., (2009), um ambiente é caracterizado por um número muito grande de fatores meteorológicos, que interagem formando o clima de uma região. Logo, em se tratando de conforto térmico animal, esses fatores não devem ser estudados de forma isolada. Deste modo, o objetivo do presente trabalho foi avaliar o efeito das variáveis meteorológicas e das dietas com diferentes níveis de feno de erva-sal e palma forrageira sobre as respostas horárias dos parâmetros fisiológicos e comportamento ingestivo dos novilhos da raça Sindi.

\section{Material e MÉTOdos}

O experimento foi conduzido no período de outubro de 2007 a janeiro de 2008, no Campo Experimental Caatinga, localizado na Embrapa Semiárido, Petrolina-PE.

Foram utilizados oito animais da raça Sindi (quatro fistulados e quatro não fistulados no rúmen), não-castrados, com uma média de doze meses de idade, oriundos do sistema extensivo de produção da caatinga, com peso corporal médio inicial de $\pm 150 \mathrm{~kg}$. Antes de iniciar o experimento, os animais foram previamente identificados com brincos numerados e vacinados contra a febre-aftosa, vermifugados, pesados e distribuídos em baías individuais (1,00m x 1,60m) cobertas com tela de polietileno preta, com capacidade de retenção de iluminação de $70 \%$, providas de comedouro, bebedouro e saleiro individuais.

As dietas experimentais foram compostas por volumosos, em quatro níveis de feno de erva-sal e palma forrageira, além de concentrado (Tabela 1).

O feno da erva-sal foi produzido na Embrapa Semiárido e a palma-forrageira cv.gigante foi adquirida em propriedade privada no município de Jutaí-PE.

O delineamento experimental utilizado foi o quadrado latino 4x4 duplo, para a avaliação do comportamento ingestivo. Já para a avaliação dos parâmetros fisiológicos foi utilizado um quadrado latino $4 \times 4$ duplo, com esquema fatorial duplo (4x12), no qual os fatores foram: quatro dietas compostas por diferentes níveis de inclusão do feno de erva-sal (15, 30, 45 e 60\%) x doze horários (01h00min; 03h00min; 05h00min; 07h00min; 09h00min; 11h00min; 13h00min; 15h00min; 17h00min; 19h00min; 21h00min e 23h00min), com quatro repetições.

Durante o experimento as dietas foram ofertadas em dois horários, as nove e às quatorze horas, permitindo uma sobra de $10 \%$. Foram recolhidos 5\% do total de alimento ofertado e 
das sobras, que foram amostradas, acondicionadas em bandejas devidamente identificadas e pré-secas em estufa de ventilação forçada, a $60^{\circ} \mathrm{C}\left( \pm 5^{\circ} \mathrm{C}\right)$, durante 72 horas.

As análises das dietas (Tabela 1) foram realizadas no Laboratório de Nutrição Animal do Centro de Ciências Agrárias da Universidade Federal da Paraíba - UFPE e no Laboratório de Nutrição Animal da Embrapa Semiárido-PE. As amostras foram processadas em moinho tipo "Willey" com peneira de $1 \mathrm{~mm}$ e foram analisadas para a determinação dos teores de matéria seca (MS), matéria mineral (MM), matéria orgânica (MO), proteína bruta (PB), extrato etéreo (EE) e sódio (Na), segundo metodologias descritas por Silva \& Queiroz (2002), e fibra em detergente neutro (FDN) e fibra em detergente ácido (FDA), através de metodologias descritas por Mertens, (2002). Foram estimados os teores de carboidratos totais (CT): [CT=100-(\%PB+\%EE+\%MM)] e carboidratos não fibrosos (CNF): [CNF=100(\%PB+\%EE+\%MM+\%FDN)] segundo metodologias descritas por Sniffen et al. (1992).

As avaliações dos parâmetros fisiológicos de frequência respiratória (FR), temperatura superficial (TS) e temperatura retal (TR), foram realizadas em doze horários pré-estabelecidos, (01:00; 03:00; 05:00; 07:00; 09:00; 11:00; 13:00; 15:00; 17:00; 19:00; 21:00 e 23:00 horas). Para a determinação da TS, utilizouse o termômetro de infravermelho a $10 \mathrm{~cm}$ de distância da pele em cinco locais distintos (fronte, pescoço, caixa torácica, flanco e pernil). Para a TR, utilizou-se termômetro clinico veterinário, introduzido a $10 \mathrm{~cm}$ no reto de cada animal por dois minutos. A FR, quantificada em número de respirações por minuto, foi obtida pela contagem da movimentação do flanco dos novilhos Sindi durante 15 segundos e multiplicando-se por quatro, obtendo-se a frequência respiratória por minuto.

No registro dos tempos despendidos em alimentação, ruminação e ócio, utilizou-se a observação visual instantânea dos animais a cada dez minutos, por quatro períodos integrais de 24 horas (Johnson \& Combs, 1991).

Para a obtenção dos dados da caracterização do ambiente térmico, utilizaram-se dados de abrigo meteorológico, obtendo-se leituras de: temperatura de bulbo seco e úmido; temperatura de globo negro; e velocidade do vento. Os dados foram coletados no décimo dia de cada período experimental, de hora em hora, durante 24 horas, sendo calculados a temperatura do ar (Tar), umidade relativa (UR), índice de temperatura e umidade (ITU) e índice de temperatura de globo negro e umidade (ITGU).

A determinação da eficiência térmica pelo índice de temperatura de globo negro e umidade (ITGU), conforme descrito por Buffington et al., (1981), foi obtida pela equação: ITGU $=0,72(\mathrm{Tg}+\mathrm{Tbu})+40,6$

em que: $\mathrm{Tg}=$ temperatura do termômetro de globo negro $\left({ }^{\circ} \mathrm{C}\right)$ e Tbu = temperatura de termômetro de bulbo úmido $\left({ }^{\circ} \mathrm{C}\right)$.

Os valores do índice de temperatura e umidade (ITU), conforme descrito por Buffington et al., (1982), foram obtidos pela equação:

ITU = 0,8 Ta + UR (Ta - 14,3)/100 + 46,3

em que Ta - temperatura do bulbo seco, ${ }^{\circ} \mathrm{C}$, e UR - umidade relativa do ar, \%.
Tabela 1. Composição química das dietas experimentais em função dos níveis de inclusão de feno de erva-sal

Table 1 Chemical composition of the experimental diets according to the level of inclusion of saltbush hay

\begin{tabular}{lcccc}
\hline \multirow{2}{*}{ Variável } & \multicolumn{4}{c}{ Feno de erva-sal (\% da MS) } \\
\cline { 2 - 5 } & 15 & 30 & 45 & 60 \\
\hline Feno de erva-sal & 15 & 30 & 45 & 60 \\
Palma forrageira & 60 & 45 & 30 & 15 \\
Concentrado & 25 & 25 & 25 & 25 \\
Farelo de soja & 0,600 & 0,400 & 0,400 & 0,198 \\
Farelo de milho & 0,316 & 0,504 & 0,520 & 0,722 \\
Uréia & 0,004 & 0,016 & - & - \\
Suplemento mineral e vitamínico & 0,080 & 0,080 & 0,080 & 0,080 \\
\hline
\end{tabular}

Composição química das dietas (\% da MS)

\begin{tabular}{lcccc} 
MS & 55,75 & 63,61 & 68,06 & 79,00 \\
MO & 84,20 & 84,20 & 82,13 & 83,65 \\
MM & 15,20 & 15,80 & 16,10 & 15,54 \\
PB & 8,74 & 12,94 & 12,07 & 9,84 \\
FDN & 34,11 & 42,53 & 41,76 & 53,25 \\
FDA & 16,51 & 21,82 & 23,76 & 28,74 \\
EE & 1,43 & 1,67 & 1,90 & 1,52 \\
CT & 74,63 & 69,59 & 69,94 & 73,10 \\
CNF & 40,53 & 27,06 & 28,18 & 19,85 \\
Na & 1,77 & 2,70 & 3,20 & 3,46 \\
\hline
\end{tabular}

MS = matéria seca; $M O=$ matéria orgânica; $M M=$ matéria mineral; $\mathrm{PB}=$ proteína bruta; FDN = fibra em detergente neutro; $F D A$ = fibra em detergente ácido; $E E$ = extrato etéreo; $C T$ = carboidratos totais; CNF = carboidratos não-fibrosos; $\mathrm{Na}=$ sódio

Os dados correspondentes aos parâmetros fisiológicos foram submetidos à analise de variância, e quando significativos, procedeu-se o teste de regressão, utilizando o programa estatístico SISVAR ${ }^{\circledR}$ (Ferreira, 2003), a 5\% de probabilidade. Já para os dados correspondentes ao comportamento ingestivo e parâmetros climáticos, procedeuse a análise descritiva.

\section{REsultados E Discussão}

A Tar apresentou mínima de $23,25^{\circ} \mathrm{C}$, encontrada às cinco da manhã, e máxima temperatura do ar de $36^{\circ} \mathrm{C}$, encontrada às 15 horas. Constatou-se que durante todo o período experimental os novilhos Sindi foram submetidos a temperaturas superiores às consideradas como confortáveis para a espécie, sujeitando-as ao estresse térmico. Segundo Nääs (1989), a faixa de temperatura ambiente confortável para a maioria dos ruminantes encontra-se entre 13 e $18^{\circ} \mathrm{C}$, recomendando-se a temperatura de 4 a $24^{\circ} \mathrm{C}$ para vacas em lactação, podendo-se restringir esta faixa aos limites de 7 a $21^{\circ} \mathrm{C}$ em função da umidade relativa e da radiação térmica.

Esta situação de estresse térmico pode ser confirmada quando se observam os valores de ITGU durante o período experimental. De acordo com o National Weather Service, citado por Baêta (1985), valores de ITGU até 74, de 74 a 78, de 79 a 84 e acima de 84, definem situação de conforto, de 


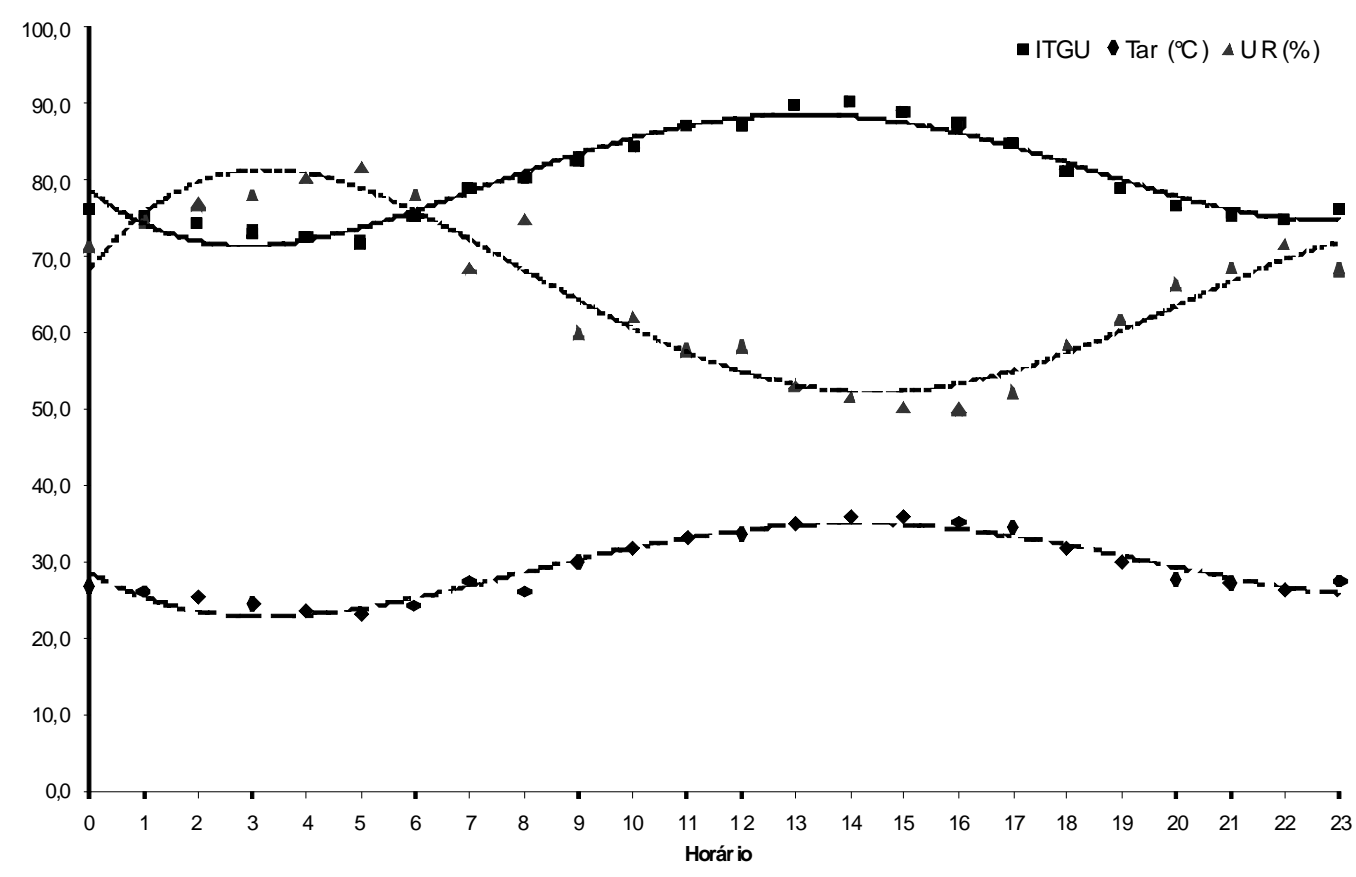

Figura 1. Valores horários do índice de temperatura de globo negro e umidade do ar (ITGU), temperatura do $\operatorname{ar}\left(\operatorname{Tar},{ }^{\circ} \mathrm{C}\right)$ e umidade relativa (UR, \%) sobre as condições do Submédio do Vale do São Francisco

Figure 1 Hourly values of the black globe temperature index and air humidity (ITGU), air temperature $\left(\operatorname{Tar},{ }^{\circ} \mathrm{C}\right)$ and relative humidity (UR) under the conditions of the Lower Basin of Vale do São Francisco, Brazil

alerta, de perigo e de emergência, respectivamente, para bovinos de leite. Observou-se que as condições climáticas durante o período experimental mantiveram-se em situação de conforto térmico apenas no período compreendido das três às cinco da madrugada com mínimo ITGU de 71,74 às 05:00h (Figura 1), alternando-se situações de alerta, perigo e emergência nos demais horários dentro das 24 horas, com ITGU máximo de 87,22 às 16:00h. Os valores de ITGU encontrados na presente pesquisa estão de acordo com os encontrados por Souza et al. (2007), que trabalhando com gado Sindi na estação seca do semiárido paraibano, observaram ITGU de 76,1 e 88,7 nos períodos da manhã e tarde, respectivamente.

Já a UR observada no presente experimento apresentouse dentro de valores considerados adequados à troca de temperatura dos novilhos com o ambiente, estando de acordo com a literatura, que menciona de 60 a 70\% (Muller, 1989; Machado \& Grodzki, 1994).

Levando-se em consideração o efeito das condições ambientais, representado pelo índice de temperatura e umidade (ITU), sobre o comportamento ingestivo dos novilhos Sindi (Figura 2), o padrão de alimentação mantevese concentrado no período diurno. Os picos de alimentação (Figura 2) foram ritmados pelos horários de fornecimento da dieta (9 e 14h), estando de acordo com Fischer et al., (2002), que trabalhando com vacas leiteiras, observaram a concentração das atividades de ingestão de alimentos entre seis e dezenove horas, atingindo os valores máximos entre nove e dez horas e entre dezessete e dezoito horas, horários de fornecimento da dieta. A concentração da atividade ingestiva durante a fase diurna do dia também foi observada em novilhas leiteiras (Deswysen et al., 1989), novilhos confinados (Ray \& Roubicek, 1971) e ruminantes sob pastejo (Fischer, 1996; Forbes, 2007).

A atividade de ruminação (Figura 3) foi mais consistente entre as 18 e 8h, horários (Figura 3) estes caracterizados por apresentar menores valores de índice de temperatura e umidade (ITU). Como as atividades de ruminação e digestão são responsáveis pela maior liberação do incremento calórico proveniente da dieta, a opção por executar esta atividade nos períodos de menor ITU pode refletir a capacidade adaptativa destes animais a regiões de clima mais quente. Por outro lado, os novilhos Sindi também apresentaram uma tendência de atividade de ruminação entre 11 e $12 \mathrm{~h}$. Ainda que menos expressiva, esta atividade coincide com o intervalo entre refeições, o que reforça a influência dos horários de fornecimento do alimento sobre o comportamento ingestivo dos novilhos Sindi para estas condições experimentais. Estes resultados estão de acordo com Deswysen et al. (1989; 1993) e Fischer et al. (2002), que encontraram atividade de ruminação mais consistente nos períodos da noite e da madrugada.

Foi observado um comportamento linear decrescente para a variável FR nas diferentes dietas experimentais (Tabela 2), nas quais os maiores teores de feno contidos nas dietas (45 e $60 \%$ de feno de erva-sal) promoveram menor FR aos animais.

A elevação da FR dos novilhos Sindi que consumiram as dietas contendo 15 e $30 \%$ de feno de erva-sal pode ter sido provocada pela maior quantidade de carboidratos não- 


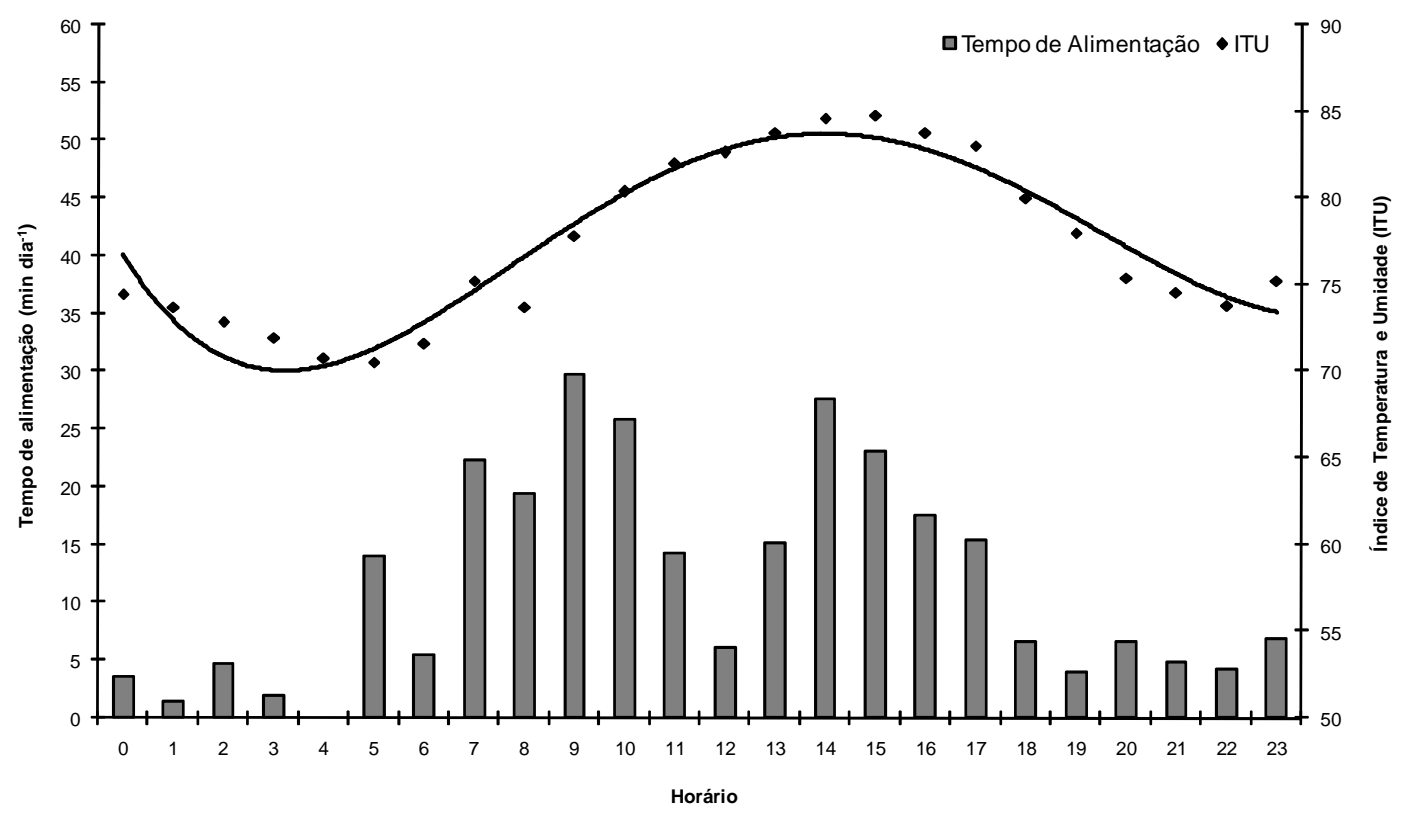

Figura 2. Valores horários do índice de temperatura e umidade do ar (ITU) e tempo de alimentação dos novilhos Sindi sobre as condições do Submédio do Vale do São Francisco

Figure2. Hourly values of the temperature and humidity index (ITU) and feeding period of the Sindi steers under the conditions of the Lower Basin of Vale do São Francisco, Brazil

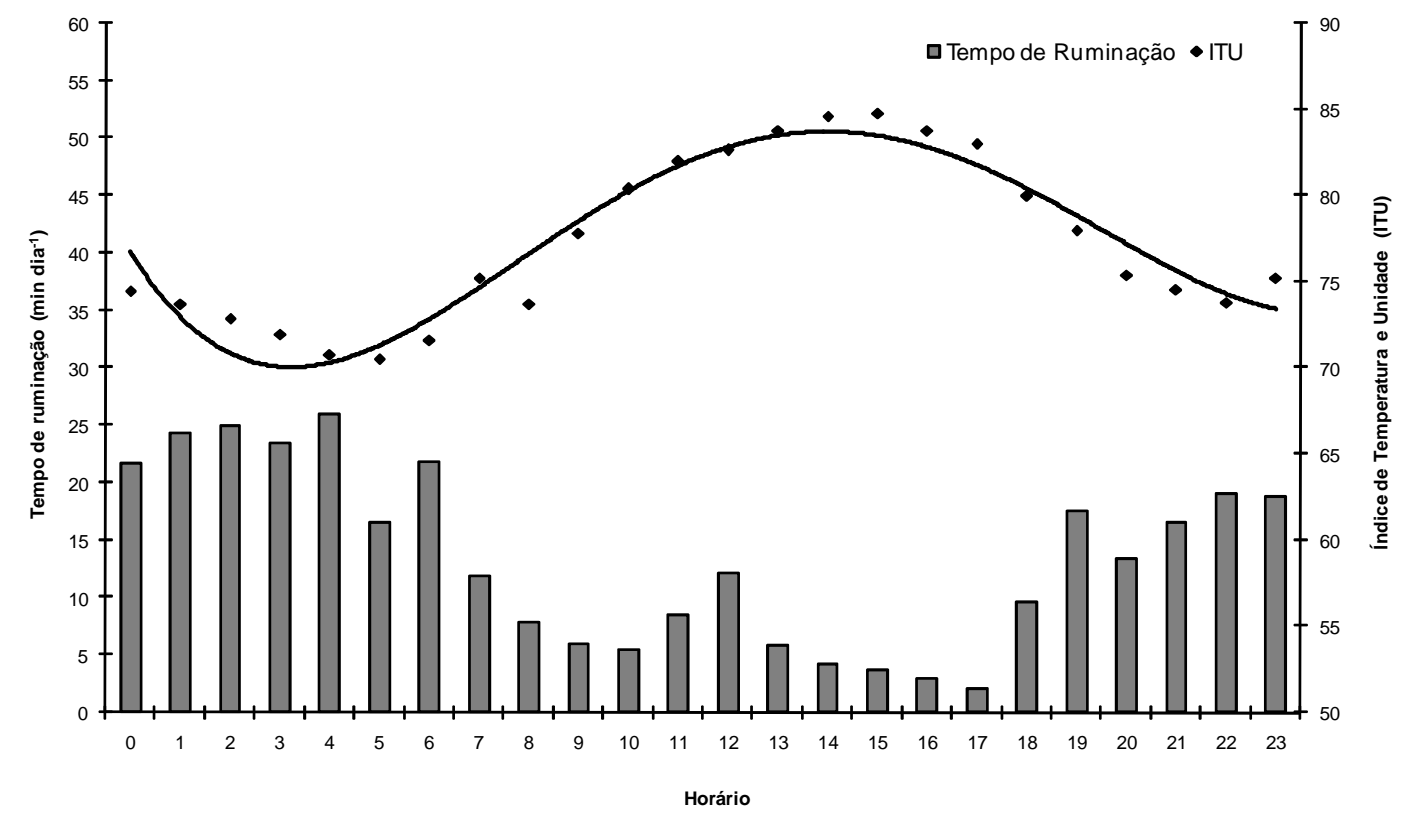

Figura 3. Valores horários do índice de temperatura e umidade do ar (ITU) e tempo de ruminação dos novilhos Sindi sobre as condições do Submédio do Vale do São Francisco

Figure 3. Hourly values of the temperature and humidity index (ITU) and rumination period of the Sindi steers under the conditions of the Lower Basin of Vale do São Francisco, Brazil 
Tabela 2. Valores médios dos parâmetros fisiológicos: frequência respiratória (FR), temperatura superficial (TS) e temperatura retal (TR) de bovinos Sindi recebendo dietas com diferentes níveis do feno de erva-sal (15, 30, 45 e 60\%)

Table2. Mean values of the physiological parameters: respiratory rate (RR), surface temperature (TS) and rectal temperature (RT) of Sindhi cattle fed diets with different levels of saltbush hay $(15,30,45$ and $60 \%)$

\begin{tabular}{|c|c|c|c|c|c|c|c|}
\hline \multirow[t]{2}{*}{ Variável } & \multicolumn{4}{|c|}{ Proporção de feno de erva-sal (\%) } & \multirow[t]{2}{*}{ ER } & \multirow[t]{2}{*}{$\mathrm{R}^{2}$} & \multirow[t]{2}{*}{$\mathrm{CV} \%$} \\
\hline & 15 & 30 & 45 & 60 & & & \\
\hline $\mathrm{FR}$ (mov./min) & 26,8 & 25,56 & 20,47 & 19,91 & $\hat{Y}=29,6291-2,5752 X$ & 0,90 & 38,43 \\
\hline $\mathrm{TS}\left({ }^{\circ} \mathrm{C}\right)$ & 32,65 & 33,04 & 32,84 & 32,54 & $\hat{Y}=32,77$ & - & 4,97 \\
\hline $\operatorname{TR}\left({ }^{\circ} \mathrm{C}\right)$ & 38,97 & 38,88 & 38,85 & 38,82 & $\hat{Y}=38,88$ & - & 1,17 \\
\hline
\end{tabular}

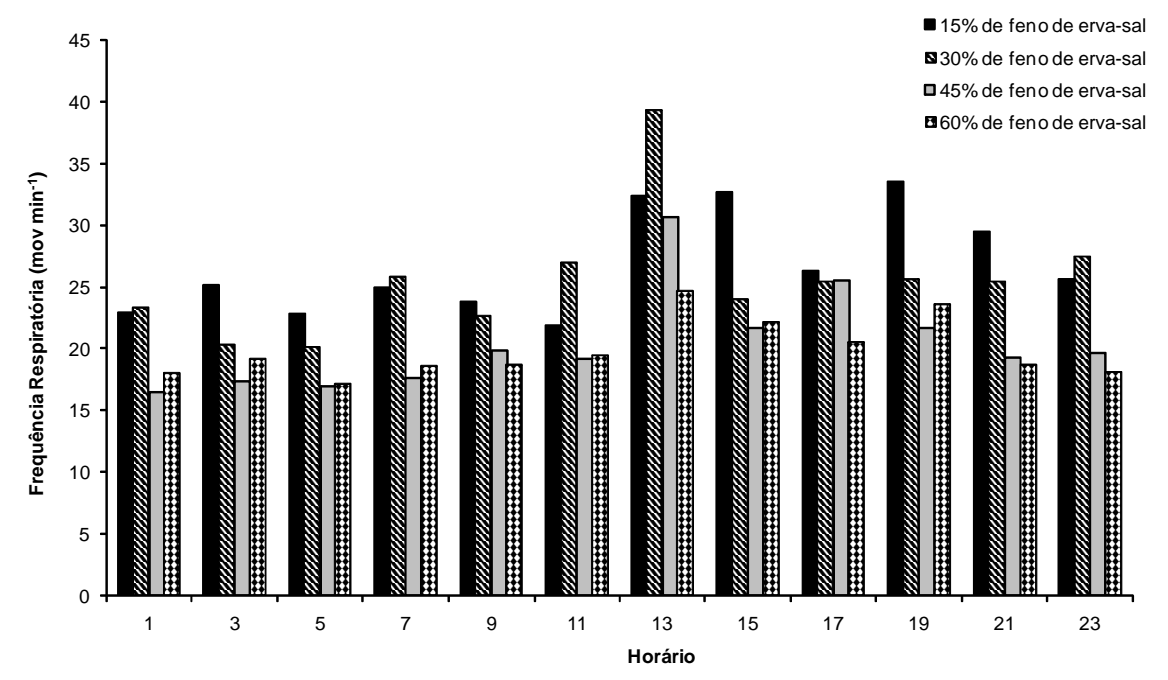

Figura 4. Valores médios horários da frequência respiratória (FR) de novilhos da raça Sindi recebendo dietas com diferentes níveis do feno de erva-sal (15, 30, 45 e 60\%) nas condições do Submédio do Vale do São Francisco

Figure 4. Mean hourly values of respiratory frequency (FR) of Sindi steers fed diets with different levels of saltbush hay (15, 30, 45 and $60 \%)$ under the conditions of the Lower Basin of Vale São Francisco, Brazil

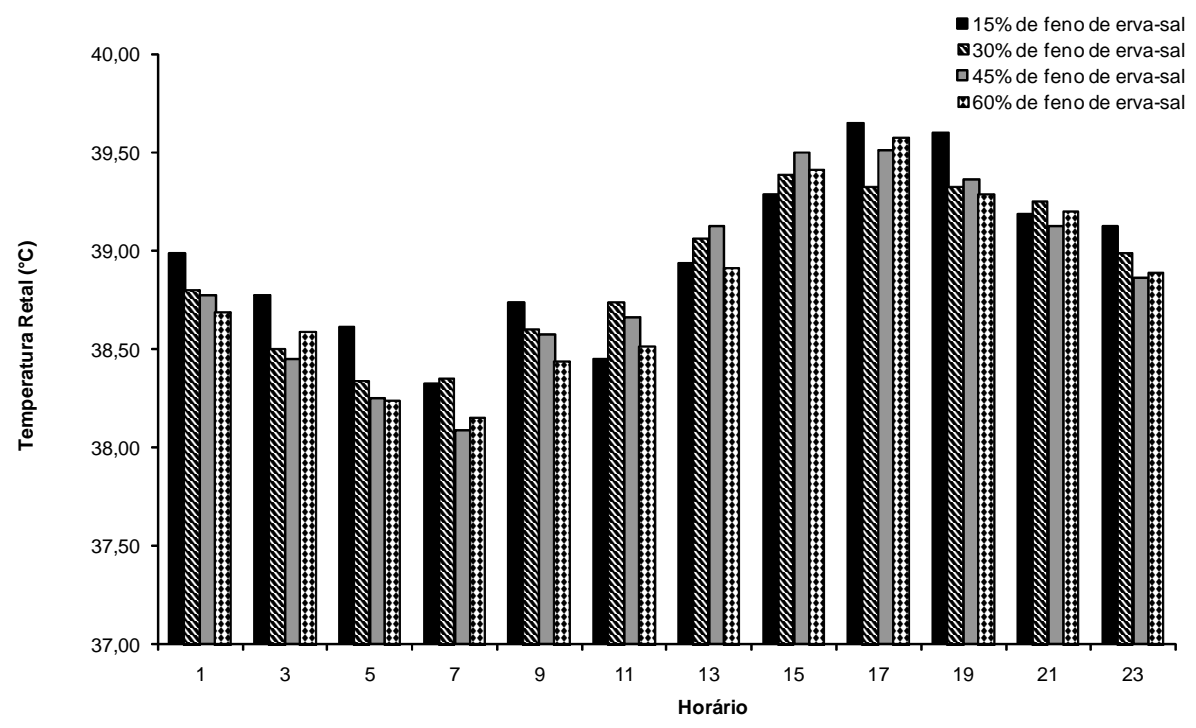

Figura 5. Valores médios horários da temperatura retal (TR) de novilhos da raça Sindi recebendo dietas com diferentes níveis de feno de erva-sal (15, 30, 45 e 60\%) nas condições do Submédio do Vale do São Francisco

Figure 5. Mean hourly values of the rectal temperature (RT) of Sindi steers fed diets with different levels of saltbush hay (15, 30, 45 and 60\%) under the conditions of the Lower Basin of Vale São Francisco, Brazil 
fibrosos (CNF) presentes nestas dietas, tratando-se de um alimento de elevada digestibilidade, permitindo uma liberação mais rápida de calor metabólico na digestão. Este aumento também pode estar relacionado com os elevados níveis de matéria orgânica (MO) presente nestas dietas (Tabela 1), indicando uma maior capacidade de fermentação, gerando mais calor. O calor excedente foi liberado através da evaporação pelas vias respiratórias, aumentando, conseguintemente, a frequência de respiração nesses tratamentos. Este mecanismo fisiológico garantiu a homeotermia dos novilhos Sindi, em relação às dietas experimentais. Estes resultados diferem dos encontrados por Pereira et al. (2008), que não observaram diferença estatística na FR de novilhas de três grupos genéticos, Holandês $(\mathrm{H})$ $\times$ Zebu (Z) $(7 / 8$ HZ, 15/16 HZ e Holandês puro por cruza HPC), recebendo dietas com níveis de fibra em detergente neutro (30 e 60\%) semelhantes aos do presente experimento. Entretanto, Pereira et al. (2008) observaram comportamento semelhante aos do presente estudo para a variável TR, a qual se manteve dentro de limites fisiológicos considerados normais em ambos os estudos.

Ao avaliar a frequência respiratória (FR) dos novilhos Sindi ao longo do dia (Figura 4), percebeu-se que, nos horários de ocorrência das maiores Tar e ITGU (Figura 3), os animais apresentaram os maiores valores de FR. Estes resultados foram observados nas diferentes dietas experimentais e indicam ainda que os novilhos Sindi, apesar da elevação da FR nos horários mais quentes do dia, apresentavam-se com FR inferior aos 60 movimentos respiratórios/minuto, considerados por Hahn et al. (1997) como o limite a partir do qual se caracterizaria o estresse térmico, estando de acordo com Azevedo et al. (2008). Turco et al. (1999), trabalhando com bovinos da raça Sindi com idade variando de um a quatro anos, obtiveram FR média de 23 a 27 movimentos respiratórios/minuto, próximos aos obtidos no presente trabalho.

A temperatura retal (Figura 5) apresentou uma elevação progressiva a partir das 7 horas, tendo seu ponto máximo às 17 horas, em todas as dietas experimentais. Isto pode ser justificado pelo acumulo de calor no organismo animal, resultante do excesso de calor recebido do ambiente, somado à produção de calor interna durante o dia e a incapacidade dos mecanismos termorreguladores em eliminar este calor excedente (Nääs, 1989). Apesar dos elevados valores de ITGU observados na Figura 1, considerados críticos, os resultados sugerem que a TR dos animais permaneceu dentro da faixa considerada normal para bovinos com mais de um ano de idade, que, segundo Kolb (1987), é de $38,5 \pm 1,5^{\circ} \mathrm{C}$. Logo, as formas de perda de calor latente foram suficientes para manter a temperatura corporal nos limites considerados normais, o que indica a adaptabilidade fisiológica dos novilhos Sindi às condições de ambiente térmico a que estavam submetidos.

Assim, considera-se que, mesmo sobre condições de estresse térmico, com médias de Tar e ITGU superiores a $29,3^{\circ} \mathrm{C}$ e 80,2 , respectivamente, os bovinos Sindi mantiveram a sua temperatura retal média em torno de $38,8^{\circ} \mathrm{C}$, padrão considerado normal para a espécie.

\section{CONCLUSÕES}

As variáveis meteorológicas ao longo do dia exercem forte influência sobre todas as respostas fisiológicas dos bovinos Sindi. A distribuição das atividades do comportamento ingestivo (alimentação, ruminação e ócio), ao longo das 24 horas, demonstra tendência a ser ritmada pelos horários de distribuição do alimento.

O consumo das dietas experimentais contendo os menores percentuais de feno de erva-sal pelos novilhos da raça Sindi proporcionou aumento na frequência respiratória dos animais, sem, no entanto alterar a temperatura retal.

\section{LITERATURA CITADA}

Azevedo, D.M.M.R.; Alves, A.A.; Feitosa, F.S.; Magalhães, J.A.; Malhado, C.H.M. Adaptabilidade de bovinos da raça pé-duro às condições climáticas do semi-árido do estado do Piauí. Archivos de Zootecnia, v. 57, n. 220, p. 513-523, 2008. <http://www.uco.es/organiza/servicios/publica/az/ php/img/web/26_18_31_13AdaptabilidadeAzevedo.pdf>. 18 Abr. 2010.

Baêta, F.C. Responses of lactating dairy cows to the combined effects of temperature, humidity and wind velocity in the warm season. Missouri: University of Missouri, 1985. 218p.

Batista, A.M.V.; Ribeiro Neto, A.C.; Lucena, R.B.; Santos, D.C.; Dubeux Jr., J.C.B.; Mustafa, A.F. Chemical composition and ruminal dry matter and crude protein degradability of spineless cactus. Journal of Agronomy and Crop Science., v. 189, n.2, p. 123-126. 2003. <http://onlinelibrary.wiley.com/ doi/10.1046/j.1439-037X.2003.00008.x/pdf >. doi:10.1046/j.1439-037X.2003.00008. 18 Abr. 2010.

Beede, D.K.; Collier, R.J. Potential nutritional strategies for intensively managed cattle during thermal stress. Journal of Animal Science, v.62, n.2, p.543-554, 1986. <http://jas.fass.org/content/62/2/543.short>. 15 Mar. 2010.

Bényei, B.; Barros, C.C.W. Variações fisiológicas de parâmetros reprodutivos em vacas de raça Holandesa importadas da Hungria para o Nordeste brasileiro. Brazilian Journal of Veterinary Research and Animal Science [on line], v.37, n.3, 2000. <http://www.scielo.br/scielo.php?pid=S141395962000000300008\&script=sci_art text $>$. doi:10.1590/S141395962000000300008. 15 Mar. 2010.

Buffington, D.E.; Collazo-Arocho, A.; Canton, G.H.; Pitt, D. Black Globe-Humidity index (BGHI) as confort equation for dairy cows. Transactions of the ASAE, v. 24, n.3, p.711714, 1981.

Buffington, D.E.; Collier, R.J.; Canton, G.H. Shede managemente systems to reduce heat stress for dairy cows. St. Joseph: American Society of Agricultural Engineers, 1982. 16 p. (Paper 82- 4061).

Chase, L.E.; Wangsness, P.J.; Baumgardt, B.R. Feeding behavior of steers fed a complete mixed ration. Journal of Dairy Science, v.59, n.11, p.1923-1928, 1976. <http://www.journalofdairyscience.org/article/S00220302(76)84462-1/abstract>. doi:10.3168/jds.S00220302(76)84462-1. 15 Fev. 2010. 
Damasceno, J.C.F.; Baccari Júnior E.L.A.T. Respostas fisiológicas e produtivas de vacas holandesas com acesso à sombra constante ou limitada. Revista da Sociedade Brasileira de Zootecnia, v.27, n.3, p.595-602, 1998. <http://www.sbz.org.br/revista/artigos/1979.pdf>. 15 Fev. 2010.

Deswysen, A.G.; Dutilleul, P.A.; Godfrin, J.P.; Ellis, W.C. Nycterohemeral eating and ruminating patterns in heifers fed grass or corn silage: analysis by finite Fourier transform. Journal of Animal Science, v. 71, n. 10, p. 2739-2747, 1993. $<$ http://jas.fass.org/content/71/10/2739.full.pdf>. 15 Fev. 2010.

Deswysen, A.G.; Duttileul, P.; Ellis, W.C. Quantitative analysis of nycterohemeral eating and ruminating patterns in heifers with different voluntary intakes and effects of monensin. Journal of Animal Science, v.67, n.10, p.2751-2761, 1989. <http://jas.fass.org/content/67/10/2751.full.pdf>. 15 Fev. 2010.

Organización de las Naciones Unidas para la Alimentación e la Agricultura - FAO. Estudios de caso de espécies vegetales para zonas áridas y semiaridas de Chile y México. Santiago: Oficina Regional de la FAO para América Latina y el Caribe, 1996. 143 p.

Ferreira, D.F. Sisvar versão 4.2. Lavras: DEX/UFLA, 2003.

Fischer, V. Efeitos do fotoperíodo, da pressão de pastejo e da dieta sobre o comportamento ingestivo de ruminantes. Porto Alegre: Universidade Federal do Rio Grande do Sul, 1996. 243p. Tese Doutorado.

Fischer, V.; Deswysen AG.; Dutilleul P.; Boever D. Padrões da distribuição nictemeral do comportamento ingestivo de vacas leiteiras, ao início e ao final da lactação, alimentadas com dieta à base de silagem de milho. Revista Brasileira de Zootecnia, v.31, n.5, p.2129-2138, 2002. <http://www.scielo. br/pdf/rbz/v31n5/a29v31n5.pdf>. doi:10.1590/S151635982002000800029. 12 Jan. 2010.

Forbes, J.M. The voluntary food intake of farm animals. Londres: Oxford, 2007. 453p.

Hahn, G.L.; Parkhurrst, A.M.; Gaughan, J.B. Cattle respiration rate as a function of ambient temperature. Transactions of American Society of Agricultural Engineering, v.40, p.97-121, 1997.

Jaster, E.H.; Murphy, M.R. Effects of varying particle size of forage on digestion and chewing behavior of dairy heifers. Journal of Dairy Science, v. 66, n. 6, p. 802-810, 1983. <http://download.journals.elsevierhealth.com/pdfs/ journals/0022-0302/PIIS0022030283818608.pdf>. doi:10.3168/ jds.S0022-0302(83)81860-8. 12 Jan. 2010.

Johnson, T.R.; Combs, D.K. Effects of prepartum diet, inert rumen bulk, and dietary polythylene glicol on dry matter intake of lactating dairy cows. Journal of Dairy Science, v. 74, n.3, p.933-944, 1991. <http://download.journals.elsevier health.com/pdfs/journals/0022-0302/PIIS002203029178243X .pdf>. doi:10.3168/jds.S0022-0302(91)78243-X. 15 Jan. 2010.

Kolb, E. Fisiologia veterinária. 4.ed. Rio de Janeiro: Guanabara Koogan, 1987. 612p.

Machado, M.S.; Grodzki, L. Aspectos climáticos regionais e a ecologia zootécnica. In: Rodrigues, A.S. (Org.). A produção animal na agricultura familiar do Centro-Sul do Paraná. Histórico da ocupação econômica do Paraná. Londrina: IAPAR, 1994. p.23-37. (Bo1etim Técnico, 42).

Martello, L.S. Respostas fisiológicas e produtivas de vacas holandesa em lactação submetidas a diferentes ambientes. Revista Brasileira de Zootecnia, v. 33, n.1, p. 181-191, 2004. <http://www.scielo.br/pdf/rbz/v33n1/a22v33n1.pdf>. doi:10.1590/S1516-35982004000100022. 16 Jan. 2010.

Mertens, D.R. Creating a system for meeting the fiber requirements of dairy cows. Journal of Dairy Science, v. 80, n.7, p.1463-1481, 1997. <http://download.journals. elsevierhealth.com/pdfs/journals/0022-0302/ PIIS0022030297760752.pdf>. doi:10.3168/jds.S00220302(97)76075-2. 12 Jan. 2010.

Mertens, D.R. Gravimetric determination of amylase-treated neutral detergent fibre in feeds with refluxing beakers or crucibles: collaborative study. Journal of AOAC International, v.85, n.6, p.1217-1240, 2002.

Muller, P.B. Bioclimatologia aplicada aos animais domesticos. Porto Alegre: Sulina, 1989. 262p.

Nääs, I.A. Princípios de conforto térmico na produção animal. São Paulo: Ícone, 1989. 183p.

Neves, M.L.M.W.; Azevedo, M. de; Costa, L.A.B.; Guim, A.; Leite, A.M.; Chagas, J.C. Níveis críticos do índice de conforto térmico para ovinos da raça Santa Inês criados a pasto no agreste do Estado de Pernambuco. Acta Scientiarum. Animal Sciences, v. 31, n. 2, p.169-175, 2009. <http://periodicos.uem.br/ojs/index.php/ActaSciAnimSci/ article/view/3766/3766> . doi:10.4025/actascianimsci.v31i2.3766. 22 Jan. 2010.

Pereira, J.C.; Cunha, D.N.F.V.; Cecon, P.R. Desempenho, temperatura retal e freqüência respiratória de novilhas leiteiras de três grupos genéticos recebendo dietas com diferentes níveis de fibra. Revista Brasileira de Zootecnia, v.37, n.2, p.328-334, 2008. <http://www.scielo.br/scielo.php? script=sciarttext\&pid=S1516-35982008000200020\&lng= pt\&nrm=iso\&tlng=pt>. doi:10.1590/S1516-35982008000200020. 22 Jan. 2010.

Pires, M.F.A. Taxa de gestação em fêmeas da raça Holandesa confinadas em free stall, no verão e inverno. Arquivo Brasileiro de Medicina Veterinária e Zootecnia, v. 54, p.5763, 2002. <http://www.scielo.br/scielo.php?script=sci_art text\&pid=S0102-09352002000100009> .doi:10.1590/S010209352002000100009. 22 Jan. 2010.

Ray, D.E.; Roubicek, C.B. Behavior of feedlot cattle during two seasons. Journal of Animal Science, v.33, n.1, p.72-76, 1971. $<$ http://jas.fass.org/content/33/1/72.full.pdf>. 20 Jan. 2010.

Santos, M.V.F.; Lira, M.A.; Farias, I.; Burity, H.A.; Tavares Filho, J.J. Efeito do período de armazenamento pós-colheita sobre o teor de matéria seca e composição química das palmas forrageiras. Pesquisa Agropecuária Brasileira, v.27, n.6, p.777-783, 1992. <http://webnotes.sct.embrapa.br/pdf/ pab1992/junho/pab01_jun_92.pdf>. 07 Nov. 2009.

Santos, R. Os cruzamentos na pecuária moderna. [S.l]: Editora Agropecuária Tropical, 1999. 120p.

Silanikove, N. Effects of heat stress on the welfare of extensively managed domestic ruminants. Livestock Production Science, v.67, p.1-18, 2000. <http:// www.sciencedirect.com/science/article/pii/S0301622600001627>. doi:10.1016/S0301-6226(00)00162-7. 05 Dez. 2009.

Silva, D.J.S.; Queiroz, A.C. Análise de alimentos químicos e biológicos. Viçosa: UFV, 2002. 235p. 
Silva, R.G. Introdução à bioclimatologia animal. São Paulo: Nobel, 2000. 286p

Sniffen, C.J; O’connor, J.D.; Van Soest, P.J. Fox, D.G.; Russell, J.B. A net carbohydrate and protein system for evaluating cattle diets: II. Carbohydrate and protein availability. Journal of Animal Science, v. 70, n. 12, p. 3562-3577, 1992. $<$ http://jas.fass.org/content/70/11/3562.full.pdf+html $>$. 12 Jan. 2010.

Souza, B.B. de; Silva, R.M.N. da; Marinho, M.L.; Silva, G. de A.; Silva, E.M.N. da; Souza, Almir P. de. Parâmetros fisiológicos e índice de tolerância ao calor de bovinos da raça Sindi no Semi-árido paraibano. Ciência e Agrotecnologia, v.31, n.3, p.883-888, 2007. <http://www.scielo.br/scielo.php?script=sci_arttext\&pid= S1413-70542007000 300040\&lng=en\&nrm=iso\&tlng=pt $>$. doi:10.1590/S1413-70542007000300040. 16 Fev. 2010.

Turco, S.H.N.; Araújo, G.G.L.; Teixeira, A.H.C.; Abreu, P.G.; Mesquita, E.; Alencar, S. C. Temperatura retal e freqüência respiratória de bovinos da raça Sindi sob condições térmicas do semi-árido brasileiro. In: Reunião Anual da Sociedade Brasileira de Zootecnia, 36. Porto Alegre. Anais... SBZ. Porto Alegre. 1999. Cd-Rom. 